\title{
Incidence of the initiation of comfort care immediately following emergent neurosurgical and endovascular procedures
}

\author{
Joseph R. Linzey, MS, ${ }^{1}$ James F. Burke, MD, ${ }^{2}$ Jeffrey L. Nadel, MS, ${ }^{1}$ Craig A. Williamson, MD, ${ }^{2,3}$ \\ Luis E. Savastano, MD, ${ }^{3}$ D. Andrew Wilkinson, MD, ${ }^{3}$ and Aditya S. Pandey, MD ${ }^{3}$ \\ ${ }^{1}$ University of Michigan Medical School; and Departments of ${ }^{2}$ Neurology and ${ }^{3}$ Neurosurgery, University of Michigan Medical \\ School, Ann Arbor, Michigan
}

\begin{abstract}
OBJECTIVE It is unknown what proportion of patients who undergo emergent neurosurgical procedures initiate comfort care (CC) measures shortly after the operation. The purpose of the present study was to analyze the proportion and predictive factors of patients who initiated CC measures within the same hospital admission after undergoing emergent neurosurgery.

METHODS This retrospective cohort study included all adult patients who underwent emergent neurosurgical and endovascular procedures at a single center between 2009 and 2014. Primary and secondary outcomes were initiation of $\mathrm{CC}$ measures during the initial hospitalization and determination of predictive factors, respectively.

RESULTS Of the 1295 operations, comfort care was initiated in 111 (8.6\%) during the initial admission. On average, CC was initiated $9.3 \pm 10.0$ days postoperatively. One-third of the patients switched to CC within 3 days. In multivariate analysis, patients $>70$ years of age were significantly more likely to undergo CC than those $<50$ years $(70-79$ years, $p=0.004 ;>80$ years, $p=0.0001)$. Two-thirds of $C C$ patients had been admitted with a cerebrovascular pathology $(p<$ $0.001)$. Admission diagnosis of cerebrovascular pathology was a significant predictor of initiating $C C(p<0.0001)$. A high Hunt and Hess grade of IV or V in patients with subarachnoid hemorrhage was significantly associated with initiation of CC compared to a low grade $(27.1 \%$ vs $2.9 \%, p<0.001)$. Surgery starting between $15: 01$ and $06: 59$ hours had a 1.70 times greater odds of initiating CC compared to surgery between 07:00 and 15:00.
\end{abstract}

CONCLUSIONS Initiation of $C C$ after emergent neurosurgical and endovascular procedures is relatively common, particularly when an elderly patient presents with a cerebrovascular pathology after typical operating hours.

https://thejns.org/doi/abs/10.3171/2018.7.JNS181226

KEYWORDS cerebrovascular pathology; comfort care; complications; emergent neurosurgery; end-of-life care; outcomes; surgical start time; vascular disorders

$\mathrm{N}$ EUROSURGICAL pathologies can cause rapid changes in a patient's neurological state, thereby requiring emergent medical and surgical intervention. Surrogate decision-makers face a challenging task-to make the best decision for their loved ones in a time-pressured, emotionally fraught environment with an inevitably incomplete understanding of prognosis and treatment options. ${ }^{7,14,28-30}$ As a consequence, consenting family members and friends often default to a do-all mentality until they are better able to absorb the full context of the patient's condition and prognosis. This, combined with the challenges of accurate prognostication during neurosurgical emergencies, ${ }^{6,7,11,21,25,38}$ often leads to decisions that favor early intervention as opposed to conservative management.

In the neurosurgical context, emergent surgery is required for a variety of conditions. Most commonly, patients undergo emergent procedures for cranial or spinal trauma, craniocerebral infections, and cerebrovascular diseases, such as subarachnoid hemorrhage ( $\mathrm{SAH})$, ischemic stroke, and intraparenchymal hemorrhage. Urgent reoperation for postoperative complications is also common. ${ }^{3}$ However,

ABBREVIATIONS CC = comfort care; EMERSE = Electronic Medical Record Search Engine; $P G Y=$ postgraduate year; $S A H=$ subarachnoid hemorrhage; $S S T=$ surgical start time.

SUBMITTED May 3, 2018. ACCEPTED July 31, 2018.

INCLUDE WHEN CITING Published online December 14, 2018; DOI: 10.3171/2018.7.JNS181226. 
despite the best efforts of the surgical team, a proportion of patients undergoing emergent neurosurgical procedures will be transitioned to comfort care (CC) postoperatively. ${ }^{11,21,26,31}$ The reasons for initiating CC after emergency intervention are diverse: poor postoperative neurological condition, better understanding of a patient's wishes after reflection, diminishing chances of a meaningful recovery, or increasing clarity in the understanding of the chances of clinical recovery.

Much of the neurosurgical literature pertaining to $\mathrm{CC}$, end-of-life care, and hospice focuses on neurooncology. ${ }^{16,19}$, 20,27,32-36 While this represents an important area of attention, it is essential to develop an overall understanding of how frequently patients initiate $\mathrm{CC}$ soon after emergent operations. Identification of such patients may prevent unnecessary emergent neurosurgical interventions and thus lead to a reduction in healthcare expenditures, as well as to alleviate preventable suffering for the patient and their loved ones. ${ }^{4,7,8,23}$ This retrospective cohort study is the first study to attempt to delineate the proportion and pattern of adult patients who underwent emergency neurosurgery to identify factors related to the initiation of CC.

\section{Methods \\ Study Design}

This retrospective cohort study included all adult patients who underwent emergent neurosurgical and endovascular procedures between 2009 and 2014 at our institution. The study is limited to a single institution due to the difficulty of reliably measuring $\mathrm{CC}$ using existing multicenter data sources. Patient medical record numbers were collected through the Data Office of Clinical \& Translational Research. Approval for this study was obtained from our local institutional review board, with a waiver of patient consent for retrospective data collection.

\section{Patient Selection}

All included patients were coded as having undergone either an "urgent" or "emergent" operation. Urgent operations were operations that occurred within 6 hours of the decision to proceed with surgery, whereas emergent operations were those that were performed within 1 hour of admission. For the purpose of this study, both urgent and emergent operations were considered as a single group because they all occurred independently of elective cases. Adult patients ( $\geq 18$ years of age) were included. All patients either presented to the emergency department or were on the inpatient service when it was determined that they required an emergent intervention.

\section{Clinical Data}

Demographic data were all obtained through the University of Michigan's Data Office of Clinical \& Translational Research. Variables included age, sex, Charlson coded comorbidities, date of procedure, day of the week (weekday vs weekend), surgical start time (SST), and CC order sets. Age was measured as an ordinal variable: < $50,50-59,60-69,70-79, \geq 80$ years. SST was analyzed as a binary variable defined as 07:00-15:00 and 15:0106:59.
$\mathrm{CC}$ was defined as cessation of life-sustaining measures and a shift in focus to maintaining the comfort and dignity of the patient. CC status was considered and assessed during the initial hospital admission. Patients who died in the hospital before $\mathrm{CC}$ was initiated were not designated as having achieved CC status. We determined CC status through a two-step verification process. At our institution, $\mathrm{CC}$ is initiated by entering a CC order set into the electronic medical record. We flagged patients for whom the CC order set was issued by attending physicians. To validate the order set entry as a reasonable metric for the initiation of CC, a free-text search of electronic medical records was performed, using the Electronic Medical Record Search Engine (EMERSE). ${ }^{9}$ The search terms "comfort care," "comfort," "care," "death," and "die" were applied across all electronic medical records to verify the initial list.

We also used EMERSE to gather patient-specific data, including presenting pathology, Hunt and Hess grade, and presence of midline shift. We coded Hunt and Hess grade as an ordinal variable and as a binary variable (low grade being I, II, or III and high grade being IV or V). We categorized the presenting pathologies into the following: 1) cerebrovascular, 2) spine, 3) neurooncology, 4) cranial trauma, 5) peripheral nerve, 6) wound care, 7) infection, and 8) other.

In most cases, neurosurgical residents were responsible for the initial discussion regarding the need for emergent surgical intervention. In order to determine which residents had this discussion, we matched the date of emergent admission with the resident call schedule. Our electronic call records were started in 2011. Thus, identification of the resident was applied only to patients admitted between 2011 and 2014 in the analysis. Residents were grouped into junior residents (postgraduate years [PGYs] 2-4) and senior residents (PGYs 5-7). Interns (PGY 1) are not on 24-hour call at our institution.

\section{Statistical Analysis}

Chi-square tests, Fisher exact tests, and t-tests were utilized to analyze the data, as appropriate. In order to evaluate the relative contributions of our measured clinical variables, a univariate logistic regression was performed for each variable against the initiation of $\mathrm{CC}$ measures. All variables with a $p$ value $<0.20$ were included in a multivariate logistic regression. Subgroup analysis was then performed by isolating the patients presenting with a cerebrovascular pathology. Univariate and multivariate logistic regression analyses were then performed on the remaining cerebrovascular data in the same manner described above to determine specific predictors of $\mathrm{CC}$ within the cerebrovascular population. We considered a two-sided $\mathrm{p}$ value $\leq$ 0.05 to be statistically significant. All data were analyzed using SAS software (SAS Institute Inc.).

\section{Results}

\section{Descriptive Analysis}

This study included 1116 patients undergoing 1295 emergent operations. The average age of the patients undergoing emergent neurosurgery was $52.4 \pm 16.1$ years, and $50.7 \%$ of the population were female. Of the 1295 


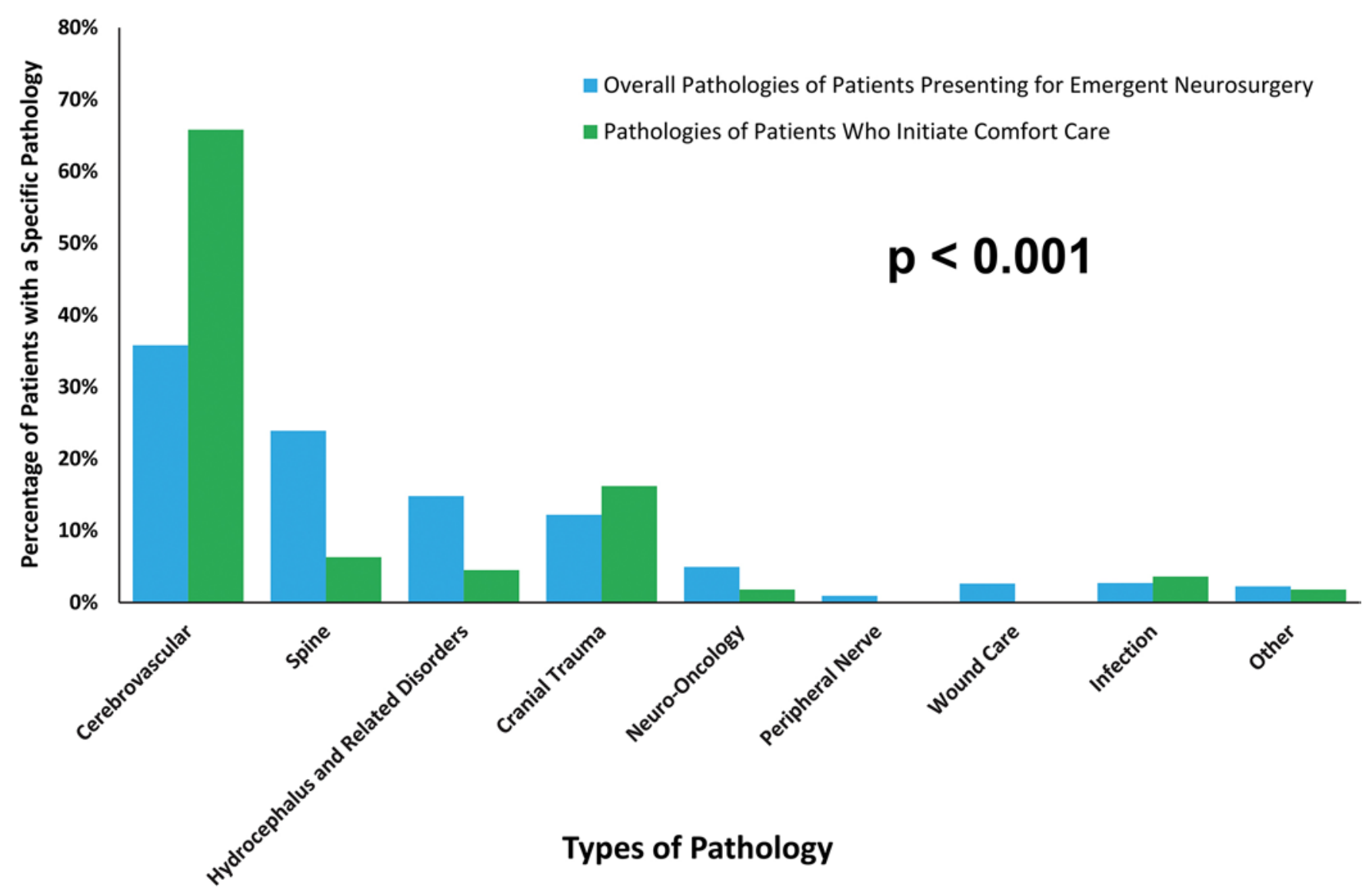

FIG. 1. Presenting pathologies compared to pathologies initiating CC. Figure is available in color online only.

operations, comfort care was initiated in $111(8.6 \%)$ during the initial admission. The majority of presenting pathologies were cerebrovascular $(35.8 \%)$, spine (23.9\%), hydrocephalus-related disorders $(14.8 \%)$, or cranial trauma (12.2\%; Fig. 1). All measured patient factors are summarized in Table 1.

Patients over the age of 70 years were significantly more likely to initiate $\mathrm{CC}$ compared to younger patients $(\mathrm{p}<$ 0.0001). Additionally, they tended to have more Charlson coded comorbidities when they presented to the hospital $(1.7 \pm 1.3$ vs $0.9 \pm 1.4 ; p<0.0001)$. Nearly $36 \%(463 / 1295)$ of the operations performed were for a cerebrovascular pathology; however, patients with a cerebrovascular pathology made up nearly two-thirds of patients who initiated CC ( $\mathrm{p}<0.001$; Fig. 1).

An SST between 15:01 and 06:59 was significantly associated with an increased initiation of CC compared to an SST between 07:00 and 15:00 ( $\mathrm{p}=0.004)$; however, there was no difference between patients initiating $\mathrm{CC}$ when they presented during the weekend compared to weekdays ( $\mathrm{p}=0.75)$ (Table 1$)$. On average, CC measures were initiated $9.3 \pm 10.0$ days postoperatively. A full third of the patients switched to CC measures within 3 days of the operation. There was no significant difference between the likelihood of junior (PGY 2, 3, or 4) versus senior (PGY 5, 6, or 7) residents involved in the care of patients undergoing initiation of $\mathrm{CC}(\mathrm{p}=0.3)$.

\section{Multivariate Analysis}

After accounting for other variables, patients aged 7079 years had 2.57 times the odds of initiating CC compared to patients $<50$ years old $(\mathrm{p}=0.0006)$. The effect of old age was further demonstrated in those older than 80 years (OR $3.69,95 \%$ CI 1.56-8.73, $\mathrm{p}=0.003$; Table 2). Additionally, compared to patients with a spinal pathology, patients presenting with a cerebrovascular pathology (OR 14.18, 95\% CI 5.76-34.88, $\mathrm{p}<0.0001$ ), infection (OR 6.04, 95\% CI $1.53-23.88, \mathrm{p}=0.01$ ), or cranial trauma (OR 5.02, $95 \% \mathrm{CI}$, $1.93-13.08, \mathrm{p}=0.001$ ) had significantly higher odds of initiating CC during the hospital admission (Table 2).

Patients with an SST between 15:01 and 06:59 were $70 \%$ more likely to initiate CC than patients with an SST between 07:00 and 15:00. Additionally, patients with more severe Charlson coded comorbidities, including congestive heart failure, hemiplegia, moderate/severe renal disease, and cancer with or without metastases, were also more likely to initiate CC (Table 2).

\section{Cerebrovascular Subanalysis}

Subanalysis of cerebrovascular pathologies demonstrated that $15.8 \%$ of all cerebrovascular patients initiated $\mathrm{CC}$ during their initial hospitalization. Multivariate logistic regression demonstrated that patients 70-79 years old had 4.08 times greater odds (95\% CI 1.59-10.51, p 
TABLE 1. Demographic information

\begin{tabular}{|c|c|c|c|}
\hline Variable & $\begin{array}{l}\text { Began CC } \\
\text { During } \\
\text { Admission } \\
(n=111)\end{array}$ & $\begin{array}{l}\text { Did Not Begin } \\
\text { CC During } \\
\text { Admission } \\
(n=1184)\end{array}$ & $\begin{array}{c}p \\
\text { Value }\end{array}$ \\
\hline Age (yrs) & & & $<0.0001$ \\
\hline$<50$ & $27(24.3 \%)$ & $479(40.5 \%)$ & \\
\hline $50-59$ & $32(28.8 \%)$ & $317(26.8 \%)$ & \\
\hline $60-69$ & $20(18.0 \%)$ & $241(20.4 \%)$ & \\
\hline $70-79$ & $21(18.9 \%)$ & $103(8.7 \%)$ & \\
\hline$\geq 80$ & $11(9.9 \%)$ & $44(3.7 \%)$ & \\
\hline Sex & & & 0.04 \\
\hline Female & $46(41.4 \%)$ & $611(51.6 \%)$ & \\
\hline \multicolumn{4}{|l|}{ Charlson coded comorbidities } \\
\hline $\begin{array}{l}\text { Chronic obstructive pulmo- } \\
\text { nary disease }\end{array}$ & $12(10.8 \%)$ & $80(6.8 \%)$ & 0.11 \\
\hline Peripheral vascular disease & $19(17.2 \%)$ & $166(14.0 \%)$ & 0.37 \\
\hline Congestive heart failure & $14(12.6 \%)$ & $50(4.2 \%)$ & $<0.0001$ \\
\hline Myocardial infarction & $8(7.2 \%)$ & $25(2.1 \%)$ & 0.001 \\
\hline Cerebrovascular disease & $54(48.7 \%)$ & $336(28.4 \%)$ & $<0.0001$ \\
\hline Hemiplegia & $20(18.0 \%)$ & $137(11.6 \%)$ & 0.05 \\
\hline Dementia & $2(1.8 \%)$ & $6(0.5 \%)$ & 0.10 \\
\hline Peptic ulcer disease & $0(0.0 \%)$ & $3(0.3 \%)$ & $>0.99$ \\
\hline Rheumatology & $0(0.0 \%)$ & $19(1.6 \%)$ & 0.40 \\
\hline Mild liver disease & $3(2.7 \%)$ & $35(3.0 \%)$ & $>0.99$ \\
\hline $\begin{array}{l}\text { Moderate/severe liver } \\
\text { disease }\end{array}$ & $1(0.9 \%)$ & $5(0.4 \%)$ & 0.48 \\
\hline $\begin{array}{l}\text { Moderate/severe renal } \\
\text { disease }\end{array}$ & $13(11.7 \%)$ & $27(2.3 \%)$ & $<0.0001$ \\
\hline $\begin{array}{l}\text { Uncomplicated diabetes } \\
\text { mellitus }\end{array}$ & $16(14.4 \%)$ & $64(5.4 \%)$ & 0.0007 \\
\hline $\begin{array}{l}\text { Complicated diabetes } \\
\text { mellitus }\end{array}$ & $0(0.0 \%)$ & $11(0.9 \%)$ & 0.61 \\
\hline Cancer w/o metastases & $13(11.7 \%)$ & $76(6.4 \%)$ & 0.04 \\
\hline Cancer w/ metastases & $9(8.1 \%)$ & $46(3.9 \%)$ & 0.03 \\
\hline Total no. of comorbidities & $1.7(1.3)$ & $0.9(1.4)$ & $<0.0001$ \\
\hline Diagnosis category & & & $<0.0001$ \\
\hline Cerebrovascular & $73(65.8 \%)$ & $390(32.9 \%)$ & \\
\hline Spine & $7(6.3 \%)$ & $303(25.6 \%)$ & \\
\hline $\begin{array}{l}\text { Hydrocephalus \& related } \\
\text { disorders }\end{array}$ & $5(4.5 \%)$ & $186(15.7 \%)$ & \\
\hline Cranial trauma & $18(16.2 \%)$ & $140(11.8 \%)$ & \\
\hline Neurooncology & $3(1.8 \%)$ & $61(5.2 \%)$ & \\
\hline Peripheral nerve & $0(0.0 \%)$ & $12(1.0 \%)$ & \\
\hline Wound care & $0(0.0 \%)$ & $34(2.9 \%)$ & \\
\hline Infection & $4(3.6 \%)$ & $31(2.6 \%)$ & \\
\hline Other & $2(1.8 \%)$ & $27(2.3 \%)$ & \\
\hline Day of week of procedure & & & 0.75 \\
\hline Weekday & $76(68.5 \%)$ & $828(69.9 \%)$ & \\
\hline Weekend & $35(31.5 \%)$ & $356(30.1 \%)$ & \\
\hline
\end{tabular}

》 CONTINUED FROM PREVIOUS COLUMN

TABLE 1. Demographic information

\begin{tabular}{lccc}
\hline & $\begin{array}{c}\text { Began CC } \\
\text { During } \\
\text { Admission } \\
\text { Variable }\end{array}$ & $\begin{array}{c}\text { Did Not Begin } \\
\text { CC During } \\
\text { Admission } \\
(n=111)\end{array}$ & $\begin{array}{c}p \\
(n=1184)\end{array}$ \\
Value \\
\hline SST & & & 0.004 \\
\hline $07: 00-15: 00$ & $35(31.5 \%)$ & $540(45.6 \%)$ & \\
\hline 15:01-06:59 & $76(68.5 \%)$ & $644(54.4 \%)$ & \\
\hline Resident level & & & 0.3 \\
\hline Junior resident & $68(77.3 \%)$ & $663(72.1 \%)$ & \\
\hline Senior resident & $20(22.7 \%)$ & $256(27.9 \%)$ & \\
\hline
\end{tabular}

$=0.004)$ of initiating $\mathrm{CC}$ than patients younger than 50 years, while those older than 80 years had 12.06 times the odds of initiating $\mathrm{CC}$ than patients younger than 50 years (95\% CI 3.42-42.59, $\mathrm{p}=0.0001$; Table 3). Patients with an SST between 15:01 and 06:59 had 2.02 times the odds of initiating CC than those with an SST between 07:00 and 15:00 (95\% CI 1.10-3.74, $\mathrm{p}=0.02$ ).

About $3 \%$ of patients with a low Hunt and Hess grade (I, II, or III) SAH initiated CC, whereas $27.1 \%$ of those patients with a high Hunt and Hess grade (IV or V) initiated CC ( $<<0.001$; Fig. 2). No patients with a Hunt and Hess grade of I or II initiated CC.

\section{Discussion}

Emergent neurosurgical procedures are common and not infrequently followed by the initiation of $\mathrm{CC}$ measures during the same hospital admission. As the cost of health care in the United States continues to increase, physicians and surgeons recognize the importance of efficient utilization of healthcare resources. ${ }^{5}$ It is estimated that healthcare costs will consume nearly $20 \%$ of the gross domestic product by $20200^{2,12}$ The amount of money spent at the end of a patient's life for procedures and critical care services is exorbitant and represents an opportunity to reduce healthcare expenditures. ${ }^{5,10,13,24}$ Patients and families who choose to proceed with neurosurgical procedures and then initiate CC measures during the same hospital admission represent a group for whom a better understanding of this situation could lead to the avoidance of the procedure and thus avoidance of the emotional suffering of patients and families and the financial burdens associated with costly neurosurgical procedures. Wright et al. ${ }^{37}$ demonstrated that early end-of-life discussions were associated with less aggressive medical care and that aggressive care was associated with worse patient quality of life and worse bereavement adjustment. However, the number of patients undergoing emergent neurosurgeries and initiation of CC measures during the same admission is unknown. We aimed to answer this question by utilizing a single-center retrospective analysis covering a 5-year period at a single large quaternary medical center. This is the first study to demonstrate that almost $9 \%$ of emergent neurosurgeries are associated with the initiation of $\mathrm{CC}$ within the same hospital admission. 
TABLE 2. Univariate and multivariate analyses for all patients

\begin{tabular}{|c|c|c|c|c|c|c|}
\hline \multirow[b]{2}{*}{ Variable } & \multicolumn{3}{|c|}{ Univariate Analysis } & \multicolumn{3}{|c|}{ Multivariate Analysis } \\
\hline & OR & $95 \% \mathrm{Cl}$ & p Value & OR & $95 \% \mathrm{Cl}$ & $p$ Value \\
\hline \multicolumn{7}{|l|}{ Age (yrs) } \\
\hline \multicolumn{7}{|l|}{$<50^{*}$} \\
\hline $50-59$ & 1.79 & $1.05-3.05$ & 0.03 & 1.44 & $0.82-2.55$ & 0.21 \\
\hline $60-69$ & 1.47 & $0.81-2.68$ & 0.21 & 1.03 & $0.54-1.97$ & 0.93 \\
\hline $70-79$ & 3.62 & $1.97-6.65$ & $<0.0001$ & 2.57 & $1.31-5.06$ & 0.006 \\
\hline$\geq 80$ & 4.44 & $2.06-9.54$ & 0.0001 & 3.69 & $1.56-8.73$ & 0.003 \\
\hline \multicolumn{7}{|l|}{ Sex } \\
\hline Female & 0.66 & $0.45-0.99$ & 0.04 & 0.64 & $0.41-1.00$ & 0.05 \\
\hline \multicolumn{7}{|l|}{ Charlson coded comorbidities } \\
\hline Chronic obstructive pulmonary disease & 1.67 & $0.88-3.17$ & 0.12 & 1.77 & $0.67-4.68$ & 0.25 \\
\hline Peripheral vascular disease & 1.27 & $0.75-2.13$ & 0.37 & & & \\
\hline Congestive heart failure & 3.27 & $1.75-6.13$ & $<0.0001$ & 2.88 & $1.03-8.06$ & 0.04 \\
\hline Myocardial infarction & 3.60 & $1.58-8.19$ & 0.002 & 2.60 & $0.87-7.82$ & 0.09 \\
\hline Cerebrovascular disease & 2.39 & $1.61-3.54$ & $<0.0001$ & 1.83 & $0.75-4.50$ & 0.19 \\
\hline Hemiplegia & 1.68 & $1.00-2.81$ & 0.05 & 2.91 & $1.29-6.53$ & 0.01 \\
\hline Dementia & 3.60 & $0.72-18.06$ & 0.12 & 1.65 & $0.18-15.30$ & 0.66 \\
\hline Mild liver disease & 0.91 & $0.28-3.01$ & 0.88 & & & \\
\hline Moderate/severe liver disease & 2.14 & $0.25-18.51$ & 0.49 & & & \\
\hline Moderate/severe renal disease & 5.68 & $2.84-11.37$ & $<0.0001$ & 6.69 & $2.37-18.87$ & 0.0003 \\
\hline Uncomplicated diabetes mellitus & 2.95 & $1.64-5.30$ & 0.0003 & 4.09 & $1.67-10.06$ & 0.002 \\
\hline Cancer w/o metastases & 1.93 & $1.04-3.61$ & 0.04 & 3.85 & $1.38-10.74$ & 0.01 \\
\hline Cancer w/ metastases & 2.18 & $1.04-4.59$ & 0.04 & 4.75 & $1.54-14.67$ & 0.007 \\
\hline Total no. of comorbidities & 1.33 & $1.19-1.50$ & $<0.0001$ & 0.45 & $0.26-0.78$ & 0.004 \\
\hline \multicolumn{7}{|l|}{ Diagnosis category } \\
\hline \multicolumn{7}{|l|}{ Spine* } \\
\hline Cerebrovascular & 8.10 & $3.68-17.85$ & $<0.0001$ & 14.18 & $5.76-34.88$ & $<0.0001$ \\
\hline Hydrocephalus \& related disorders & 1.16 & $0.36-3.72$ & 0.80 & 1.80 & $0.54-5.97$ & 0.34 \\
\hline Cranial trauma & 5.57 & $2.27-13.60$ & 0.0002 & 5.02 & $1.93-13.08$ & 0.001 \\
\hline Neurooncology & 1.42 & $0.29-7.00$ & 0.67 & 1.65 & $0.32-8.58$ & 0.55 \\
\hline Peripheral nerve & $<0.001$ & $0.00-99.99$ & 0.99 & $<0.001$ & $0.00-99.99$ & 0.99 \\
\hline Wound care & $<0.001$ & $0.00-99.99$ & 0.99 & $<0.001$ & $0.00-99.99$ & 0.99 \\
\hline Infection & 5.59 & $1.55-20.15$ & 0.009 & 6.04 & $1.53-23.88$ & 0.01 \\
\hline Other & 3.21 & $0.64-16.20$ & 0.16 & 3.59 & $0.67-19.20$ & 0.14 \\
\hline \multicolumn{7}{|l|}{ Day of week of procedure } \\
\hline \multicolumn{7}{|l|}{ Weekday* } \\
\hline Weekend & 1.07 & $0.70-1.63$ & 0.75 & & & \\
\hline \multicolumn{7}{|l|}{ SST } \\
\hline \multicolumn{7}{|l|}{ 07:00-15:00* } \\
\hline $15: 01-06: 59$ & 1.82 & $1.20-2.76$ & 0.005 & 1.70 & $1.08-2.67$ & 0.02 \\
\hline \multicolumn{7}{|l|}{ Resident level } \\
\hline \multicolumn{7}{|l|}{ Junior resident* } \\
\hline Senior resident & 0.76 & $0.45-1.28$ & 0.30 & & & \\
\hline
\end{tabular}

* Indicates that this is a reference category.

A number of factors are associated with the initiation of $\mathrm{CC}$ shortly after an emergent neurosurgical intervention. As would be expected, patients older than 70 years had significantly greater odds of initiating $\mathrm{CC}$ than younger patients. This could be explained by the fact that such pa- tients have a poorer chance of recovery and a shorter life expectancy. We also identified that patients who had an SST outside of typical operating times were also significantly more likely to initiate CC measures. We have previously reported an increased incidence of surgical com- 
TABLE 3. Univariate and multivariate analyses for patients with a cerebrovascular pathology

\begin{tabular}{|c|c|c|c|c|c|c|}
\hline \multirow[b]{2}{*}{ Variable } & \multicolumn{3}{|c|}{ Univariate Analysis } & \multicolumn{3}{|c|}{ Multivariate Analysis } \\
\hline & OR & $95 \% \mathrm{Cl}$ & $p$ Value & OR & $95 \% \mathrm{Cl}$ & $\mathrm{p}$ Value \\
\hline \multicolumn{7}{|l|}{ Age (yrs) } \\
\hline \multicolumn{7}{|l|}{$<50^{*}$} \\
\hline $50-59$ & 1.65 & $0.80-3.40$ & 0.17 & 1.95 & $0.87-4.37$ & 0.10 \\
\hline $60-69$ & 1.43 & $0.64-3.19$ & 0.38 & 1.21 & $0.50-2.95$ & 0.68 \\
\hline $70-79$ & 4.64 & $1.97-10.93$ & 0.0004 & 4.08 & $1.59-10.51$ & 0.004 \\
\hline$\geq 80$ & 10.82 & $3.56-32.85$ & $<0.0001$ & 12.06 & $3.42-42.59$ & 0.0001 \\
\hline \multicolumn{7}{|l|}{ Sex } \\
\hline Female & 0.50 & $0.31-0.84$ & 0.008 & 0.62 & $0.34-1.14$ & 0.12 \\
\hline \multicolumn{7}{|l|}{ Charlson coded comorbidities } \\
\hline Chronic obstructive pulmonary disease & 1.16 & $0.56-2.41$ & 0.69 & & & \\
\hline Peripheral vascular disease & 0.41 & $0.23-0.74$ & 0.003 & 0.38 & $0.17-0.83$ & 0.02 \\
\hline Congestive heart failure & 1.88 & $0.93-3.80$ & 0.08 & 1.03 & $0.37-2.81$ & 0.96 \\
\hline Myocardial infarction & 2.65 & $1.04-6.75$ & 0.04 & 1.58 & $0.46-5.43$ & 0.47 \\
\hline Cerebrovascular disease & 0.71 & $0.42-1.19$ & 0.19 & 0.86 & $0.42-1.78$ & 0.69 \\
\hline Hemiplegia & 1.49 & $0.80-2.75$ & 0.21 & & & \\
\hline Dementia & 2.70 & $0.24-30.11$ & 0.42 & & & \\
\hline Mild liver disease & 0.19 & $0.03-1.46$ & 0.11 & 0.21 & $0.02-1.81$ & 0.15 \\
\hline Moderate/severe liver disease & $<0.001$ & $0.00-99.99$ & 0.99 & & & \\
\hline Moderate/severe renal disease & 5.00 & $2.07-12.06$ & 0.0003 & 6.99 & $2.17-22.55$ & 0.001 \\
\hline Uncomplicated diabetes mellitus & 2.34 & $1.17-4.71$ & 0.02 & 1.75 & $0.72-4.29$ & 0.22 \\
\hline Cancer w/o metastases & 1.85 & $0.71-4.83$ & 0.21 & & & \\
\hline Cancer w/ metastases & 1.56 & $0.50-4.87$ & 0.45 & & & \\
\hline Total no. of comorbidities & 1.04 & $0.90-1.20$ & 0.62 & & & \\
\hline \multicolumn{7}{|l|}{ Cerebrovascular pathology } \\
\hline \multicolumn{7}{|l|}{ Subarachnoid hemorrhage* } \\
\hline Intraparenchymal hemorrhage & 2.35 & $1.25-4.43$ & 0.008 & 1.39 & $0.64-3.02$ & 0.40 \\
\hline Stroke & 2.94 & $1.52-5.68$ & 0.001 & 1.49 & $0.68-3.27$ & 0.32 \\
\hline Other & 0.14 & $0.02-1.08$ & 0.06 & 0.13 & $0.02-1.01$ & 0.05 \\
\hline \multicolumn{7}{|l|}{ Day of week of procedure } \\
\hline \multicolumn{7}{|l|}{ Weekday* } \\
\hline Weekend & 0.81 & $0.47-1.40$ & 0.45 & & & \\
\hline \multicolumn{7}{|l|}{ Surgical start time } \\
\hline \multicolumn{7}{|l|}{$07: 00-15: 00^{*}$} \\
\hline 15:01-06:59 & 1.90 & $1.12-3.22$ & 0.02 & 2.02 & $1.10-3.74$ & 0.02 \\
\hline \multicolumn{7}{|l|}{ Resident level } \\
\hline \multicolumn{7}{|l|}{ Junior resident* } \\
\hline Senior resident & 0.89 & $0.49-1.63$ & 0.71 & & & \\
\hline
\end{tabular}

plications following operations with a late SST.15 These differences could reflect surgeon fatigue, the more chaotic nature of a night encounter, or the desire for heroic operations that may have been declined during the day. It could also represent the fact that, at our institution, the neurosurgical resident serves as the primary person offering surgery during "off hours," whereas the entire team, including neurosurgical attending personnel, is available for discussion with the family during "on-hour" presentations. During off-hours there may be a tendency for trainees without significant neurosurgical experience to be overly cautious and thus offer surgical interventions to gravely ill patients whose prognosis is poor that would not have been offered in the presence of an experienced attending surgeon. Such a hypothesis is best tested and evaluated with further analysis regarding the qualitative decision-making by family members regarding the initiation of $\mathrm{CC}$ measures.

The majority of the patients who initiated $\mathrm{CC}$ presented with a cerebrovascular pathology, and, as would be expected, markers of more severe cerebrovascular illness (higher Hunt and Hess grade) were associated with increased likelihood of initiating CC. Nearly $16 \%$ of all 


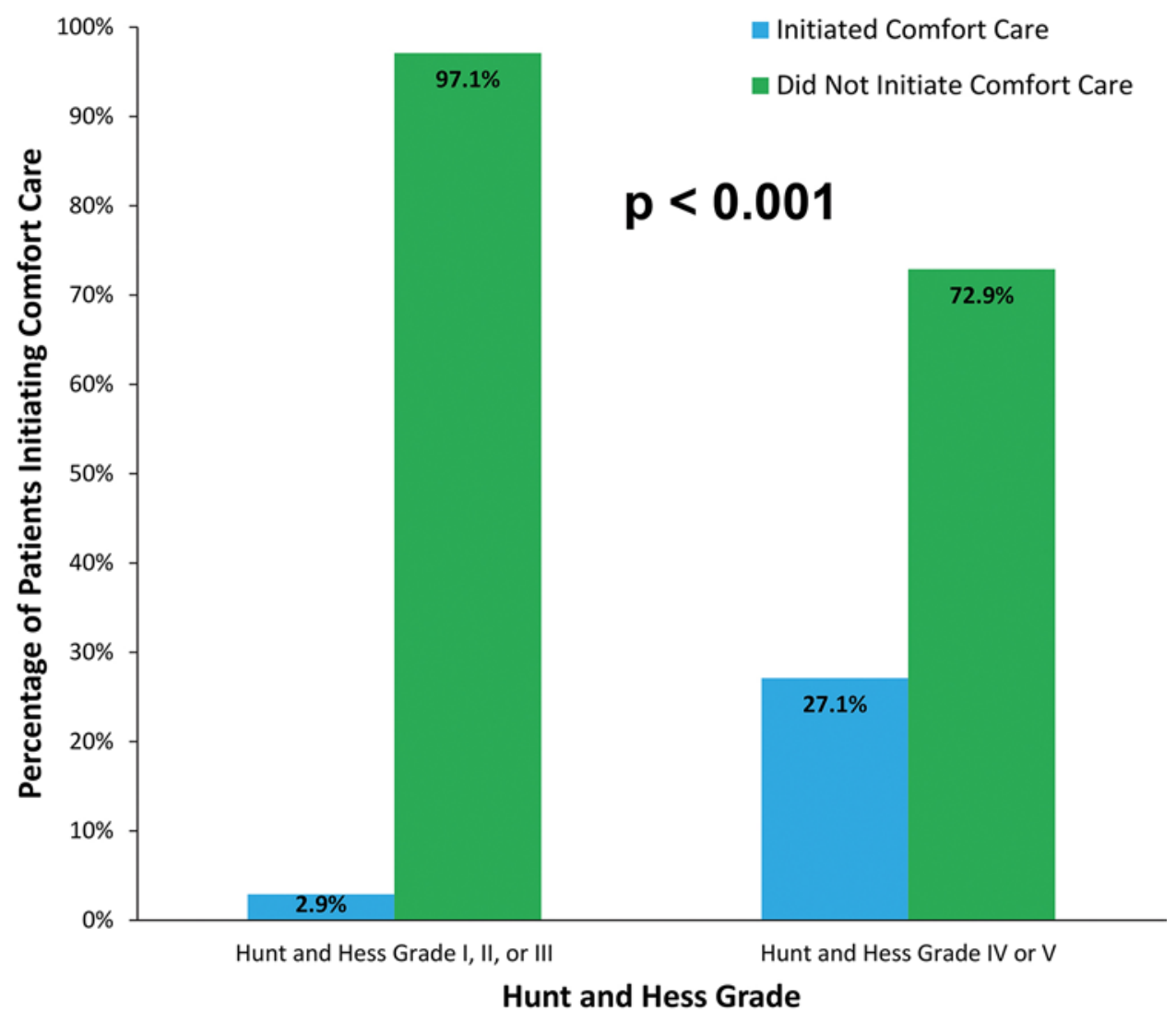

FIG. 2. Percentage of patients presenting with SAH who initiated comfort care according to Hunt and Hess grade. Figure is available in color online only.

patients with a cerebrovascular pathology initiated CC during their initial hospitalization. While emergencies occur in all neurosurgical subspecialties, cerebrovascular emergencies are often more common and disabling. Given that cerebrovascular pathologies present with sudden emergent symptoms, there is often little time for families to adequately deliberate regarding end-of-life care if the topic has not been previously discussed, potentially increasing the likelihood for aggressive interventions. In a retrospective analysis of stroke-related deaths, Quadri et al. ${ }^{23}$ reported that only $1.6 \%$ of the patients had preexisting advanced care planning. The lack of advanced care planning coupled with the sudden, disorienting nature of intraparenchymal hemorrhage and stroke often leaves patients and loved ones with little idea of how to best proceed with medical planning. As a surgeon, making end-of-life decisions for incapacitated patients is complicated due to unclear prognosis and individual surgeons' anecdotal experiences with certain pathologies. ${ }^{26}$ There is often significant variation among surgeons over how aggressively to treat the emergent patient for whom an accurate prognosis is difficult to make. . $^{, 38}$

Surgeon variability in recommending $\mathrm{CC}$ has been studied and demonstrates that focused training in palliative care measures is associated with an increased utilization of CC. ${ }^{34}$ Since palliative care training is accumulated throughout residency, we hypothesized that there would be an increased utilization of CC measures among senior residents. However, when we looked at the trends of CC initiation according to the seniority of the resident taking primary responsibility for the patient, we did not see any difference between junior and senior residents. This discrepancy could be explained by a number of factors: 1) junior residents take the majority of calls at our institution and thus deal with the majority of emergent cases (the study may have been insufficiently powered to detect a difference), 2) the increased skill and comfort level of senior residents may predispose them to an aggressive approach to treatment, or 3) formal palliative care training may be lacking throughout residency.

The initiation of $\mathrm{CC}$ is a multifaceted decision that should ideally take into account the medical condition of the patient and the expressed desires of the patient and loved ones. We demonstrate that patients who were older and who had more medical comorbidities were more likely to initiate $\mathrm{CC}$ during their initial admission. In addition, patients with more severe cerebrovascular pathologies (high Hunt and Hess grade) were significantly more likely to initiate CC. However, without preexisting advanced care planning, even with the knowledge that older, sicker patients with more severe pathology are more likely to initiate $\mathrm{CC}$, it is difficult to delineate which patients should be operated on and which should immediately enter CC upon admission.

While this study focused on the initiation of CC following an emergent operation, future studies will focus on the 
proportion of patients who are referred to the neurosurgical department and immediately initiate CC measures without undergoing an operation. This companion study will allow us to more fully understand and compare the types of patients who undergo an operation and then enter CC compared to those who are never offered surgery and proceed directly into CC. Further research efforts should be invested into understanding the qualitative decisionmaking of patients and providers concerning whether to operate or initiate CC measures. Additionally, the recently expanded window for stroke intervention will likely alter the proportion of patients presenting with a cerebrovascular pathology who initiate CC measures. ${ }^{1,18}$ These differences should be quantified in further research studies.

This study is limited by the retrospective nature of the analysis, the possibility that not all emergent operations were properly coded to reflect their emergent nature, and the possibility that not all cases of $\mathrm{CC}$ were identified. Failing to identify $\mathrm{CC}$ orders would potentially bias our results toward underrepresentation of the true utilization of CC measures, whereas inaccurate coding of routine versus emergent cases could lead to an overrepresentation. However, we attempted to negate this limitation by identifying $\mathrm{CC}$ both through comfort care order sets and through individual chart review via EMERSE. ${ }^{9}$ In addition, the proportion of our population that entered CC was relatively similar to other published reports looking at disease-specific initiation of CC. ${ }^{17,22}$ Also, we were limited by the granularity of details we were able to obtain, including the presence of an advanced directive, the degree of family involvement, the utilization of inpatient palliative care, and the baseline disease severity. In the future, we hope to design a prospective study to gather detailed data regarding disease severity for a more robust analysis. Additionally, since we selected only those patients who had an urgent or emergent operation, we did not capture the portion of the population who initiated $\mathrm{CC}$ without first undergoing an emergent operation. Last, this study is limited by the lack of qualitative analysis that could potentially illuminate the reasoning of the patient and/or surgeons in the decision to operate and subsequently initiate CC.

\section{Conclusions}

Initiation of $\mathrm{CC}$ after emergent neurosurgical and endovascular procedures in the same hospital admission is a relatively common occurrence, particularly when the patient presents with a cerebrovascular pathology, thus presenting an opportunity for better resource utilization within this patient population.

\section{Acknowledgments}

This study was supported by a TL1 Training Grant (J.R.L. and J.L.N.; 1-TL1-TR-002242-01) and an NS-007222 grant (D.A.W.), both from the National Institutes of Health.

\section{References}

1. Albers GW, Marks MP, Kemp S, Christensen S, Tsai JP, Ortega-Gutierrez S, et al: Thrombectomy for stroke at 6 to 16 hours with selection by perfusion imaging. N Engl J Med 378:708-718, 2018
2. Berwick DM, Hackbarth AD: Eliminating waste in US health care. JAMA 307:1513-1516, 2012

3. Byrne RW, Bagan BT, Slavin KV, Curry D, Koski TR, Origitano TC: Neurosurgical emergency transfers to academic centers in Cook County: a prospective multicenter study. Neurosurgery 62:709-716, 2008

4. Choi HA, Fernandez A, Jeon SB, Schmidt JM, Connolly ES, Mayer SA, et al: Ethnic disparities in end-of-life care after subarachnoid hemorrhage. Neurocrit Care 22:423-428, 2015

5. Garrido MM, Balboni TA, Maciejewski PK, Bao Y, Prigerson HG: Quality of life and cost of care at the end of life: The role of advance directives. J Pain Symptom Manage 49:828-835, 2015

6. Geurts M, de Kort FAS, de Kort PLM, van Tuijl JH, Kappelle LJ, van der Worp HB: Predictive accuracy of physicians' estimates of outcome after severe stroke. PLoS One 12:e0184894, 2017

7. Geurts M, Macleod MR, van Thiel GJ, van Gijn J, Kappelle LJ, van der Worp HB: End-of-life decisions in patients with severe acute brain injury. Lancet Neurol 13:515-524, 2014

8. Guha R, Boehme A, Demel SL, Li JJ, Cai X, James ML, et al: Aggressiveness of care following intracerebral hemorrhage in women and men. Neurology 89:349-354, 2017

9. Hanauer DA, Mei Q, Law J, Khanna R, Zheng K: Supporting information retrieval from electronic health records: A report of University of Michigan's nine-year experience in developing and using the Electronic Medical Record Search Engine (EMERSE). J Biomed Inform 55:290-300, 2015

10. Huynh TN, Kleerup EC, Wiley JF, Savitsky TD, Guse $\mathrm{D}$, Garber BJ, et al: The frequency and cost of treatment perceived to be futile in critical care. JAMA Intern Med 173:1887-1894, 2013

11. Izzy S, Compton R, Carandang R, Hall W, Muehlschlegel S: Self-fulfilling prophecies through withdrawal of care: do they exist in traumatic brain injury, too? Neurocrit Care 19:347363, 2013

12. Keehan SP, Sisko AM, Truffer CJ, Poisal JA, Cuckler GA, Madison AJ, et al: National health spending projections through 2020: economic recovery and reform drive faster spending growth. Health Aff (Millwood) 30:1594-1605, 2011

13. Kelley AS, Ettner SL, Morrison RS, Du Q, Wenger NS, Sarkisian CA: Determinants of medical expenditures in the last 6 months of life. Ann Intern Med 154:235-242, 2011

14. Lewis A, Varelas P, Greer D: Prolonging support after brain death: When families ask for more. Neurocrit Care 24:481487, 2016

15. Linzey JR, Burke JF, Sabbagh MA, Sullivan S, Thompson BG, Muraszko KM, et al: The effect of surgical start time on complications associated with neurological surgeries. Neurosurgery 83:501-507, 2018

16. Miranda SP, Bernacki RE, Paladino JM, Norden AD, Kavanagh JE, Palmor MC, et al: A descriptive analysis of end-oflife conversations with long-term glioblastoma survivors. Am J Hosp Palliat Care 35:804-811, 2018

17. Muñoz Venturelli P, Wang X, Zahuranec DB, Lavados PM, Stapf C, Lindley R, et al: Withdrawal of active treatment after intracerebral haemorrhage in the INTERACT2 study. Age Ageing 46:329-332, 2017

18. Nogueira RG, Jadhav AP, Haussen DC, Bonafe A, Budzik RF, Bhuva P, et al: Thrombectomy 6 to 24 hours after stroke with a mismatch between deficit and infarct. $\mathbf{N}$ Engl J Med 378:11-21, 2018

19. Noh T, Walbert T: Brain metastasis: clinical manifestations, symptom management, and palliative care. Handb Clin Neurol 149:75-88, 2018

20. Pace A, Dirven L, Koekkoek JAF, Golla H, Fleming J, Rudà $R$, et al: European Association for Neuro-Oncology (EANO) 
guidelines for palliative care in adults with glioma. Lancet Oncol 18:e330-e340, 2017

21. Paratz ED, Flynn E: Rapid death after admission to palliative care. Intern Med J 42:984-989, 2012

22. Prabhakaran S, Cox M, Lytle B, Schulte PJ, Xian Y, Zahuranec D, et al: Early transition to comfort measures only in acute stroke patients: Analysis from the Get With The Guidelines-Stroke registry. Neurol Clin Pract 7:194-204, 2017

23. Quadri SZ, Huynh T, Cappelen-Smith C, Wijesuriya N, Mamun A, Beran RG, et al: Reflection on stroke deaths and endof-life stroke care. Intern Med J 48:330-334, 2018

24. Ramsey S, Blough D, Kirchhoff A, Kreizenbeck K, Fedorenko C, Snell K, et al: Washington State cancer patients found to be at greater risk for bankruptcy than people without a cancer diagnosis. Health Aff (Millwood) 32:1143-1152, 2013

25. Rubin M, Bonomo J, Hemphill JC III: Intersection of prognosis and palliation in neurocritical care. Curr Opin Crit Care 23:134-139, 2017

26. Schaller C, Kessler M: On the difficulty of neurosurgical end of life decisions. J Med Ethics 32:65-69, 2006

27. Sison J, Tran H, Margol A, Tiwari N, Garcia KM, Cotter J, et al: Palliative care options for a young adult patient with a diffuse intrinsic pontine glioma. Cureus 9:e1580, 2017

28. Souter M, Van Norman G: Ethical controversies at end of life after traumatic brain injury: defining death and organ donation. Crit Care Med 38 (9 Suppl):S502-S509, 2010

29. Tawil I, Brown LH, Comfort D, Crandall CS, West SD, Rollstin AD, et al: Family presence during brain death evaluation: a randomized controlled trial. Crit Care Med 42:934-942, 2014

30. Tin MK, French P, Leung KK: The needs of the family of critically ill neurosurgical patients: a comparison of nurses' and family members' perceptions. J Neurosci Nurs 31:348356, 1999

31. Unterhofer C, Hartmann S, Freyschlag CF, Thomé C, Ortler $\mathrm{M}$ : Severe head injury in very old patients: to treat or not to treat? Results of an online questionnaire for neurosurgeons. Neurosurg Rev 41:183-187, 2018

32. Walbert T: Integration of palliative care into the neurooncology practice: patterns in the United States. Neurooncol Pract 1:3-7, 2014
33. Walbert T, Chasteen K: Palliative and supportive care for glioma patients. Cancer Treat Res 163:171-184, 2015

34. Walbert T, Glantz M, Schultz L, Puduvalli VK: Impact of provider level, training and gender on the utilization of palliative care and hospice in neuro-oncology: a North-American survey. J Neurooncol 126:337-345, 2016

35. Walbert T, Khan M: End-of-life symptoms and care in patients with primary malignant brain tumors: a systematic literature review. J Neurooncol 117:217-224, 2014

36. Walbert T, Pace A: End-of-life care in patients with primary malignant brain tumors: early is better. Neuro-oncol 18:7-8, 2016

37. Wright AA, Zhang B, Ray A, Mack JW, Trice E, Balboni T, et al: Associations between end-of-life discussions, patient mental health, medical care near death, and caregiver bereavement adjustment. JAMA 300:1665-1673, 2008

38. Zahuranec DB, Fagerlin A, Sánchez BN, Roney ME, Thompson BB, Fuhrel-Forbis A, et al: Variability in physician prognosis and recommendations after intracerebral hemorrhage. Neurology 86:1864-1871, 2016

\section{Disclosures}

The authors report no conflict of interest concerning the materials or methods used in this study or the findings specified in this paper.

\section{Author Contributions}

Conception and design: Pandey, Linzey, Burke. Acquisition of data: Pandey, Linzey, Burke. Analysis and interpretation of data: Pandey, Linzey, Burke, Savastano. Drafting the article: all authors. Critically revising the article: all authors. Reviewed submitted version of manuscript: all authors. Approved the final version of the manuscript on behalf of all authors: Pandey. Statistical analysis: Pandey, Linzey, Burke, Nadel. Administrative/technical/material support: Pandey. Study supervision: Pandey, Burke.

\section{Correspondence}

Aditya S. Pandey: University of Michigan, Ann Arbor, MI. adityap@med.umich.edu. 